\title{
Cephalometric measurements in snorers, non-snorers, and patients with sleep apnoea
}

\author{
F Maltais, G Carrier, Y Cormier, F Sériès
}

\begin{abstract}
Cephalometry is often used to assess patients with sleep apnoea but whether these measurements differ from those in non-apnoeic snorers and how they are influenced by age is not clear. Cephalometric radiographs of patients with sleep apnoea were compared with those of snorers without sleep apnoea and those of non-snorers. Fifty two snorers with suspected sleep apnoea had a conventional sleep study and were divided into two groups: those with an apnoea-hypopnoea index greater than $10 / \mathrm{h}(\mathrm{n}=40$, sleep apnoea group) and those whose apnoea-hypopnoea index was $10 / \mathrm{h}$ or less ( $\mathrm{n}=12$, snorer group). The cephalometric measurements in these patients were compared with those of 34 non-snoring control subjects. Controls were subdivided into two groups: control group 1 included 17 subjects similar in age to the sleep apnoea and snorer groups (mean (SD) age 50.0 (10.9), $50.7(9.4)$, and $50.6(9.7)$ years); control group 2 included 15 young men (25.4 (2.6) years). The distance from the mandibular plane to the hyoid bone (MP-H) and the length of the soft palate were greater in the patients with sleep apnoea $(28.7(7.8)$ and $43.6(5.0) \mathrm{mm})$ than in the snorers (23.7 (4.2) and $40.3(4.9) \mathrm{mm})$. The MP-H was similar in snorers and age matched control subjects, but was significantly greater in the older than in the younger control subjects $(22 \cdot 1(6 \cdot 1)$ vs $17 \cdot 0(6 \cdot 8))$. The soft palate was longer in subjects who snored (both sleep apnoea patients and snorers) than in control subjects. The MP-H distance significantly correlated with age for all subjects (snorers and controls) and for the control subjects alone. This study shows that non-apnoeic snorers have cephalometric abnormalities that differ from those of patients with sleep apnoea and that cephalometric values are influenced by the subject's age.
\end{abstract}

Unité de recherche, Centre de

Pneumologie, Hôpital

et Université Laval,

Sainte-Foy (Québec)

Canada G1V 4 G5

F Maltais

G Carrier

Y Cormier

F Sériès

Reprint requests to:

Dr Sériès

Accepted 14 February 1991 sure gradient (Bernoulli principle) and the instability of the upper airways. In addition, these structural abnormalities decrease the operating length of the pharyngeal dilator muscles, compromising their mechanical efficiency. ${ }^{1} \mathrm{~A}$ reduction in pharyngeal area predisposes to the development of a sleep apnoea syndrome. ${ }^{2-4}$ These upper airway abnormalities may be subtle and detectable only by computed tomography, ${ }^{5}$ acoustic reflection, ${ }^{6}$ or cephalometry. ${ }^{7-13}$

Patients with sleep apnoea commonly have cephalometric abnormalities by comparison with younger control subjects. It is not known, however, if cephalometric measurements are influenced by age. Studies using cineradiography ${ }^{14}$ and acoustic reflection ${ }^{6}$ have found upper airway abnormalities in snorers without sleep apnoea. Symptomless snorers have cephalometric abnormalities, ${ }^{15}$ but their measurements have not been compared with those from patients with sleep apnoea. We have compared the cephalometric measurements obtained in snorers with and without the sleep apnoea syndrome and in young and older normal non-snorers. Our objectives were to determine which measurements were most abnormal in patients with obstructive sleep apnoea and in snorers, and to determine whether age influences these measurements.

\section{Methods}

SUBJECTS

Eighty four white men were included in the study. Fifty two subjects were referred to our sleep laboratory for investigation of snoring and symptoms suggesting the sleep apnoea syndrome (morning headaches, nocturnal awakings and chokings, poor sleep quality, daytime somnolence). The other 32 subjects were recruited from the cardiopulmonary staff of our institution; all were non-snorers (according to their spouse or other family members) and had no clinical evidence of the sleep apnoea syndrome.

\section{STUDY DESIGN}

Lateral cephalometric radiographs were obtained for each subject with the technique described by Riley et al. ${ }^{7}$ The conventional landmarks were determined (fig 1) with the subject's head in the neutral position, eyes looking directly forward at a film tube distance of exactly 60 inches $(152 \mathrm{~cm})$. Dental prostheses were removed for cephalometric measurements in the 20 subjects who had them (18 with sleep apnoea, two snorers). All radiographs were interpreted by the same investigator (GC), who did not know the 
Figure 1 Cephalogram of a normal subject indicating the different cephalometric landmarks and

measurements. S: sella;

$N$ : nasion; $A N S$ : anterior nasal spine; PNS:

posterior nasal spine;

A: subspinale;

$B$ : supramentale;

Gn: gnathion

$M$ : mandibular plane;

$P A S$ : posterior airway

space; $S N A$ : angle

measurement from sella to

nasium to point $A ; S N B$.

angle measurement from

sella to nasium to point $B$;

$A N B$ : difference between

$S N A$ and $S N B$;

$N$-ANS : vertical

measurement from nasium

to anterior nasal spine;

ANS-Gn: vertical

measurement from anterior nasal spine to gnathion;

$M P-H:$ distance from

point $H$ (hyoid) to

mandibular plane;

$P N S-P$ : distance from

posterior nasal spine to tip

of the soft palate.

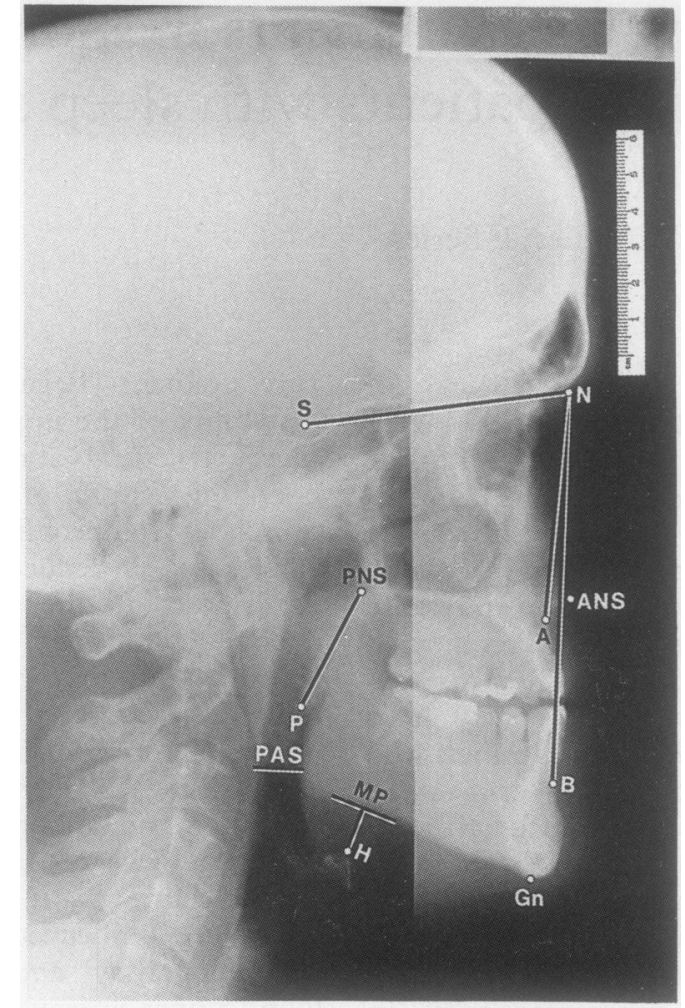

group to which the subject belonged.

Each snorer $(n=52)$ had a conventional night time polygraphic recording. The recorded variables were: electroencephalogram $\left(C_{4} A_{1}, C_{3} A_{2}\right)$, electro-oculogram, submental electromyogram, electrocardiogram, nasal and mouth flows with thermistors, thoracoabdominal movements with an inductance vest (Respitrace; Ambulatory Monitoring Inc, Ardsley, New York), and oxygen saturation $\left(\mathrm{SaO}_{2}\right)$ with a Biox II A or Biox 3700 ear oximeter. In 41 patients intrathoracic pressure was measured with an oesophageal balloon. All measurements were recorded on a 16 channel polygraph (Model 78; Grass Instruments, Quincy, Montana) at a paper speed of $10 \mathrm{~mm} / \mathrm{s}$. The body mass index (weight/height ${ }^{2}$ ) was used as an index of obesity. ${ }^{16}$

Obstructive apnoea was defined as the complete cessation of airflow for at least 10 seconds associated with thoracoabdominal paradox or inspiratory efforts, or both. Hypopnoea consisted of a reduction in airflow with a decrease in $\mathrm{SaO}_{2}$ of at least $5 \%$. The apnoea index and

Table 1 Mean (SD) values for the anthropometric characteristics and the cephalometric measurements for each group

\begin{tabular}{|c|c|c|c|c|}
\hline & $\begin{array}{l}\text { Patients with } \\
\text { sleep apnoea }\end{array}$ & Snorers & Control 1 & Control 2 \\
\hline $\begin{array}{l}\text { Age (y) } \\
\text { BMI (kg/m²) } \\
\text { SNA (deg) } \\
\text { SNB (deg) } \\
\text { ANB (deg) } \\
\text { N-ANS (mm) } \\
\text { ANS-Gn (mm) }\end{array}$ & $\begin{array}{r}50.0(10.9)^{a} \\
37.9(9.7)^{a} \\
81.6(4.5) \\
79.3(4.3) \\
3.2(2.0) \\
54.9(6.2) \\
74.7 \quad(7.4)\end{array}$ & $\begin{array}{l}50 \cdot 7(9 \cdot 4)^{\mathrm{a}} \\
27 \cdot 0(3 \cdot 7)^{\mathrm{b}} \\
80 \cdot 4(4 \cdot 0) \\
78 \cdot 6(4 \cdot 1) \\
2 \cdot 7(1 \cdot 5) \\
54 \cdot 6(4 \cdot 9) \\
75 \cdot 2(7 \cdot 1)\end{array}$ & $\begin{array}{l}50.5(8.9)^{\mathrm{a}} \\
22.7(3.8)^{\mathrm{b}} \\
79.6(4.5) \\
78 \cdot 2(4.5) \\
2.8(1.9) \\
55.3(3.0) \\
73.5(8.4)\end{array}$ & $\begin{array}{l}25 \cdot 4(2 \cdot 6)^{b} \\
22 \cdot 9(2 \cdot 8)^{b} \\
82 \cdot 0(4 \cdot 2) \\
80 \cdot 2(3 \cdot 1) \\
3 \cdot 3(2 \cdot 2) \\
56 \cdot 4(4 \cdot 0) \\
74 \cdot 4(6 \cdot 0)\end{array}$ \\
\hline
\end{tabular}

BMI-body mass index; see figure 1 for other abbreviations. Values followed by $a$ and $b$ are significantly different ( $p<0.05$, ANOVA and Student-Newman-Keuls test). apnoea-hypopnoea indices were defined by the frequency of these events per hour of sleep. ${ }^{17}$ Sleep apnoea was diagnosed when the apnoeahypopnoea index was over $10 .^{18}$ Obstructive events accounted for most apnoeic and hypopnoeic respiratory abnormalities in all our subjects.

The 84 subjects were divided into four groups: (1) those with obstructive sleep apnoea $(n=40)$; (2) snorers with an apnoeahypopnoea index of 10 or less $(n=12)$; (3) non-snorers similar in age to the patients with sleep apnoea and the snorers (control group 1, $\mathrm{n}=17$ ); and (4) young non-snorers (control group $2, \mathrm{n}=15$ ).

\section{STATISTICAL ANALYSIS}

Differences between the four groups for age, body mass index, and cephalometric measurements were assessed first by an analysis of variance (ANOVA) and then by a StudentNewman-Keuls test for multiple comparisons when ANOVA showed a significant difference between the different groups. For the comparison of two groups (patients with sleep apnoea and snorers) we used an unpaired Student's $t$ test for parametric variable (total sleep time) and a Mann-Whitney $U$ test for non-parametric variables (sleep stages, apnoea index, apnoea-hypopnoea index, mean sleeping $\mathrm{SaO}_{2}$ ). Correlation analysis between age and cephalometric measurements was done by linear regression by the least squares method.

\section{Results}

Anthropometric characteristics of the different groups are given in table 1 . The mean age was similar in the patients with sleep apnoea, snorers, and control group 1. By definition, subjects in control group 2 were younger than those in the other groups. The body mass index was significantly higher in those with sleep apnoea than in the snorers of either control group. The body mass index was similar in the snorers and the two control groups.

The results of the sleep studies obtained in the patients with sleep apnoea and the snorers are shown in table 2. The total sleep time was similar in the two groups. Patients with sleep

Table 2 Mean (SE) results of the polysomnographic studies on patients with obstructive sleep apnoea and snorers

\begin{tabular}{lrc}
\hline & $\begin{array}{l}\text { Patients } \\
\text { with } \\
\text { sleep } \\
\text { apnoea }\end{array}$ & \multicolumn{1}{c}{ Snorers } \\
\hline Total sleep time (h) & $5 \cdot 5(0 \cdot 2)$ & $6 \cdot 0(0 \cdot 3)$ \\
Stage I-II (\% total sleep time) & $82.0(2 \cdot 0)$ & $76 \cdot 1(2 \cdot 7)^{\star}$ \\
Stage III-IV (\% total sleep time) & $7 \cdot 2(1 \cdot 2)$ & $10 \cdot 1(2 \cdot 0)$ \\
Stage REM (\% total sleep time) & $9 \cdot 7(1 \cdot 0)$ & $13 \cdot 1(1 \cdot 2)$ \\
Apnoea index (n/h) & $24 \cdot 4(3 \cdot 8)$ & $1.9(0 \cdot 7) \dagger$ \\
Apnoea-hypopnoea index (n/h) & $53 \cdot 7(5 \cdot 3)$ & $3 \cdot 4(0 \cdot 8) \dagger$ \\
Arterial oxygen saturation (\%) & $87.4(1 \cdot 3)$ & $92 \cdot 5(0 \cdot 1) \dagger$ \\
\hline
\end{tabular}

${ }^{*} \mathrm{p}<0.05 ;$ † $\mathrm{p}<0.01$ (unpaired $t$ test or Mann-Whitney U test: see "Statistical analysis"). 
$\operatorname{MP-H}(\mathbf{m m})$

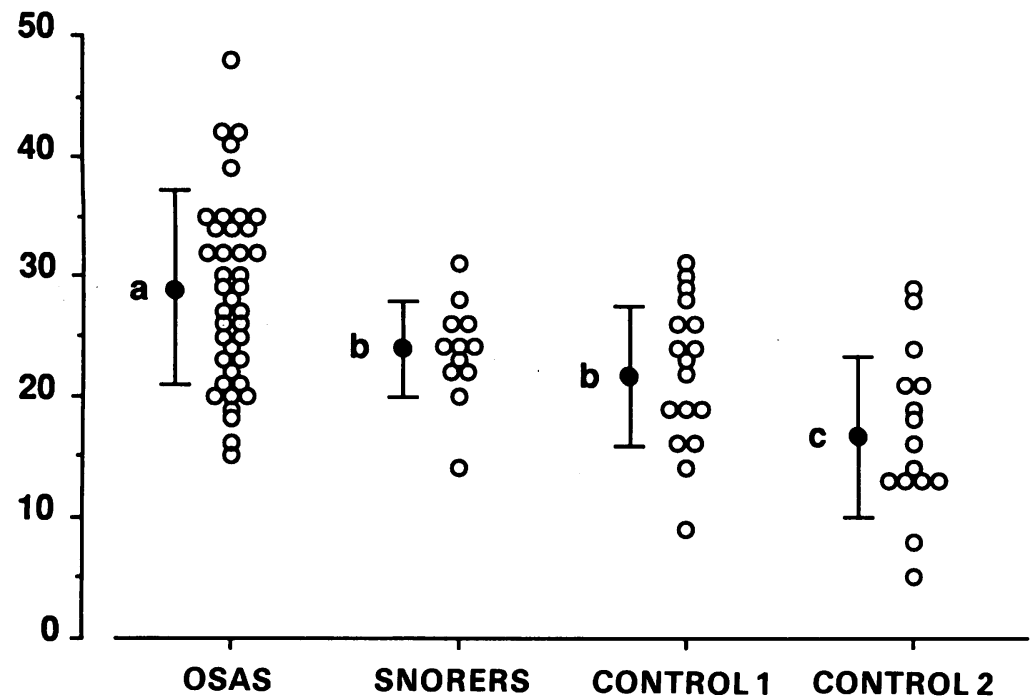

Figure 2 Individual and mean (SD) values for the distance from the hyoid bone to the mandibular plane (MP-H) in the four groups. Patients with sleep apnoea (OSAS) had the longest MP-H distance while the shortest distance was measured in young nonsnorers (control group 2). Mean values with different letters are significantly different (analysis of variance-see text for p values).

apnoea spent more of their sleep time in stage I-II than did the snorers.

Cephalometric data are summarised in table 1 for the non-significant variables and presented in more detail in figures 2 and 3 for those variables showing significant differences between the groups. The only cephalometric measurements to show significant differences were the distance from the hyoid bone to the mandibular plane (MP-H), the posterior airay space, and the length of the soft palate. Patients with sleep apnoea had a longer MP-H distance than subjects in the other groups $(p<0.05)$;

\section{DISTANCE $(\mathrm{mm})$}

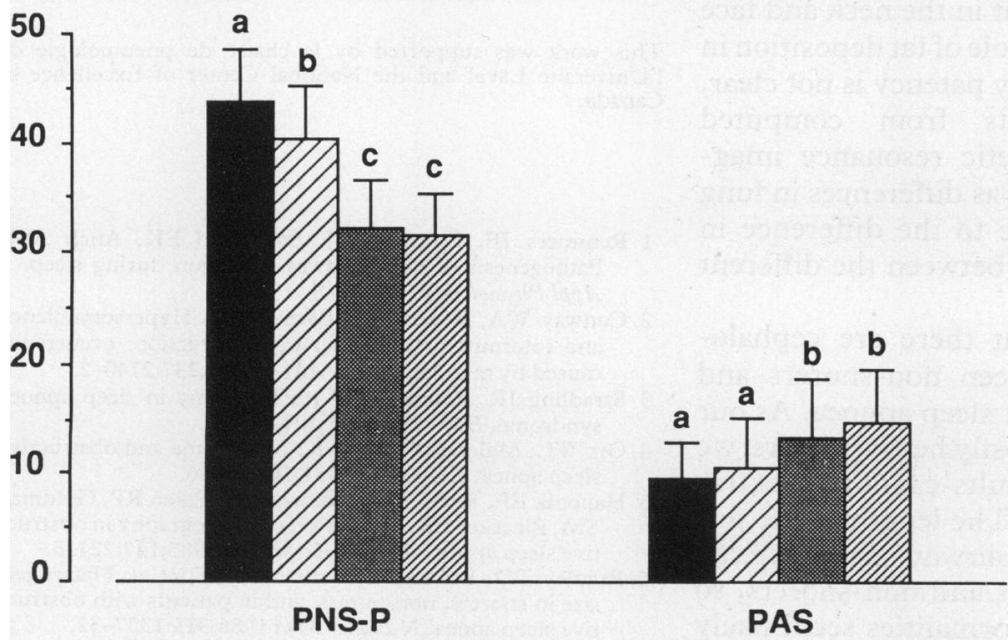

Figure 3 Mean (SD) values for the length of the soft palate (PNS-P) and the posterior airway space (PAS) in the four groups ( patients with sleep apnoea; Z snorers; 圆 control group 1; 团 control group 2). PNS-P was shorter in the control groups than in those with sleep apnoea or in snorers; the smallest PAS values were observed in those with sleep apnoea. Mean values with different letters are significantly different (analysis of variance-see text for $p$ values). snorers and age matched control subjects had similar MP-H values. The MP-H was smaller in younger control subjects than in the snorers $(\mathrm{p}<0.01)$ and the older control subjects $(\mathrm{p}<0.05)$. The soft palate was longer in subjects with sleep apnoea than in the snorers ( $p<0.05$ - - see figure 3-and longer in those with sleep apnoea and in the snorers than in either control group $(p<0.01)$. Patients with sleep apnoea tended to have a smaller posterior airway space than snorers, but the difference was not significant; it was, however, smaller in both groups of snorers than in the control subjects ( $p<0.05)$-figure 3.

There was a significant relation between age and the MP-H distance in the two control groups, who differed only by age (fig 4 ). This relation was also observed when all four groups were included in the analysis. The length of the soft palate and the posterior airway space were not correlated with age.

\section{Discussion}

Our results confirm that cephalometric measurements of snorers without sleep apnoea and patients with sleep apnoea differ from those of non-snorers, and show that, among normal subjects, MP-H distance increases with age.

Although objective measurements of snoring have been suggested, ${ }^{19-21}$ there are no standard criteria to differentiate snorers from nonsnorers. As the aim of this study was not to quantify snoring but to look at the cephalometric differences between subjects with clinically important snoring and habitual non-snorers, the selection of snorers and nonsnorers was done by questionnaire. Snoring was observed in obstructive sleep apnoea patients and in snorers by definition as they were referred to us for heavy snoring. Snoring was always confirmed by the technician during the polysomnographic study. The presence of snoring was assessed in a similar way in previous reports on the pharyngeal properties of snorers. ${ }^{62223}$ As the occurrence of snoring has been determined by questionnaire in large epidemiological studies, ${ }^{24} 25$ and as subjects in the control groups did not snore, even occasionally, we believe that any substantial overlap between our snoring and non-snoring groups is unlikely.

We do not believe that the presence or absence of dental prostheses can account for the differences between the patients with sleep apnoea and the snorers as differences were observed even if we considered only subjects without a prosthesis. In these two groups (sleep apnoea and snoring), the results of cephalometric measurements were very similar in those with and without a dental prosthesis. This is presumably because cephalometry was standardised with the mandibule in the neutral position, the lips relaxed, and the teeth not clenched.

We used cephalometric radiographs to assess the upper airway anatomy because it is simpler than other methods of measuring upper airway patency (acoustic reflection, computed tomography, magnetic resonance imaging). 


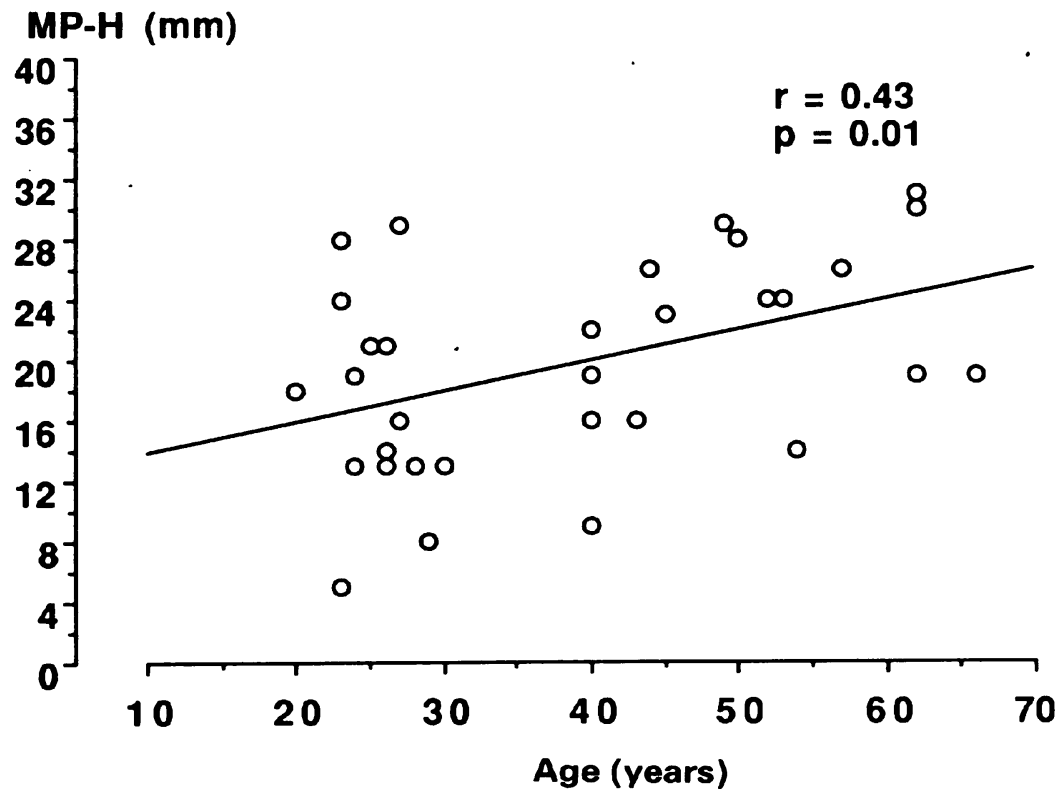

Figure 4 Relation between age and distance from the hyoid bone to the mandibular plane (MP-H) in normal subjects (both control groups), showing a significant correlation $(p=0.01)$.
The position of the hyoid bone may be an important determinant of obstructive sleep apnoea because it anchors the musculature of the tongue. When this bone is abnormally low (increasing the MP-H distance) the tongue positioned further back, ${ }^{30}$ thus reducing upper airway patency, and adding to the effect of a longer soft palate. The role of the position of the hyoid bone in obstructive apnoea is shown by the effectiveness of surgery to advance the hyoid in the treatment of sleep apnoea. ${ }^{31}$

Although anatomical factors play an important part in the development of obstructive sleep apnoea, other factors, such as an increase in pharyngeal compliance $e^{23}$ and fluctuations in the activity of the pharyngeal dilatators ${ }^{32}$ and in upper airway resistance when respiratory drive, is changed ${ }^{33}$ can account for the absence of sleep apnoea in some snorers with a small pharynx. The large overlap in cephalometric measurements between those with sleep apnoea and snorers limits the usefulness of these radiographs in screening for sleep apnoea.

The MP-H distance was longer in the age matched control subjects than in the younger control group and the relation between MP-H and age was significant. This is consistent with the results of Brown et al, who found a decrease in pharyngeal cross sectional area with age. ${ }^{27}$ These changes may be related to changes in lung volumes, fat deposition in the upper airway, or upper airway adaptation with aging, or some combination of these. This finding emphasises the need to compare cephalometric measurements of subjects of similar ages.

Cephalometric measurements in our study were obtained with the subjects in the sitting position. Fitzpatrick et al have recently reported changes in upper airway dimensions with position (that is, sitting versus supine). ${ }^{34}$ This position dependence of upper airway dimensions could be related to the effects of gravity on upper airway structures and to the lung volume dependence of upper airway patency. ${ }^{635}$ Further studies need to look at the position dependence of cephalometric measurements in those with sleep apnoea snorers, and non-snorers.

This work was supported by la chaire de pneumologie de l'Université Laval and the National Center of Excellence of Canada. determining upper airway patency is not clear, with conflicting results from computed tomography $y^{5}$ and magnetic resonance imaging. ${ }^{29}$ Other factors, such as differences in lung volumes, may contribute to the difference in upper airway dimension between the different groups. ${ }^{6}$

Our results show that there are cephalometric differences between non-snorers and snorers with and without sleep apnoea. As our snoring subjects were mostly heavy snorers, we are aware that these results cannot be extrapolated to every snorer. The length of the soft palate and the posterior airway space differed between snoring subjects and non-snorers, so these cephalometric abnormalities seem likely to be associated with snoring. In contrast, MP$\mathrm{H}$ distance was significantly greater in patients with sleep apnoea than in either heavy snorers or older control subjects, suggesting that this abnormality is more specific to sleep apnoea.
1 Remmers JE, Degroot WJ, Sauerland EK, Anch AM. Pathogenesis of upper airway occlusion during sleep. $J$ Appl Physiol 1978;44:931-8. and intermittent upper airway obstruction: occurrence

3 Stradling JR. Avoidance of tracheostomy in sleep apnoea syndrome. $B M J$ 1982;285:407-8.

4 Orr WC, Males JL, Imes NK. Myxedema and obstructive sleep apnea. Am J Med 1981;70:1061-6.

5 Haponik EF, Smith PL, Bohlman ME, Allen RP, Goldman SM, Bleecker ER. Computerized tomography in obstructive s.tep apneá. Am Rev Respir Dis 1983;127:221-6.

6 Bradley TD, Brown IG, Grossman RF, et al. Pharyngeal tive sleep apnea. $N$ Engl J Med 1986;315:1327-31.

7 Riley $R$ Guilleminault $C$ Herran J, Powell $N$ Cephalometric analyses and flow-volume loops in obstructive sleep apnea patients. Sleep 1983;6:304-17.

8 Jamieson A, Guilleminault C, Partinen M, Quera-Salva $M$. Obstructive sleep apneic patients have craniomandibular

9 Djupesland G, Lyberg T, Krogstad O. Cephalometric
2 Conway WA, Bower GC, Barnes ME. Hypersomnolence caused by micrognathia. $J A M A$ 1977;237:2740-2. size in snorers, nonsnorers, and in patients with obstrucabnormalities. Sleep 1986;9:469-77. 
analysis and surgical treatment of patients with obstructive sleep apnea syndrome. Acta Otolaryngol (Stockh) 1987;103:551-7.

10 Lyberg T, Krogstad O, Djupesland G. Cephalometric analysis in patients with obstructive sleep apnoea syndrome. 1-Skeletal morphology. J Laryngol Otol 1989; 103:287-92.

11 Lyberg T, Krogstad O, Djupesland G. Cephalometric analysis in patients with obstructive sleep apnoea syndrome. 2-Soft tissue morphology. J Laryngol Otol 1989; 103:293-7.

12 Strelzow VV, Blanks RHI, Basile A, Strelzow AE. Cephalometric airway analysis in obstructive sleep apnea syndrome. Laryngoscope 1988;98:1149-58.

13 DeBerry-Borowiecki B, Kukwa A, Blanks RHI. Cephalometric analysis for diagnosis and treatment of obstructive sleep apnea. Laryngoscope 1988;98:226-34.

14 Cirignotta F, Lugaresi E. Some cineradiographic aspects of snoring and obstructive apneas. Sleep 1980;3:225-6.

15 Schäfer J, Sieron J, Pirsig W, Haase S, Lupberger A. Radiocephalometric findings and duration of snoring in habitual snorers and obstructive apnea syndrome. Laryngorhinootologie 1989;68:163-8.

16 Khosla T, Lowe FR. Indices of obesity derived from body weight and height. Br J Prev Soc Med 1967;21:121-8.

17 Guilleminault C, Cummiskey J, Dement WC. Sleep apnea syndrome: recent advances. Adv Intern Med 1980;26: 347-72.

18 Bradley TD, Martinez D, Rutherford R, et al. Physiological determinants of noctural arterial oxygenation in patients with obstructive sleep apnea. J Appl Physiol 1985;59: 1364-8.

19 Lugaresi E, Mondini S, Zucconi M, Montagna P, Cirignotta F. Staging of heavy snorers' disease. A proposal. Bull Eur Physiopathol Respir 1983;19:590-4.

20 Berry RB, Block AJ. Positive nasal airway pressure eliminates snoring as well as obstructive sleep apnea. Chest 1984;85:15-20.

21 Hoffstein V, Chaban R, Cole P, Rubinstein I. Snoring and upper airway properties. Chest 1988;94:87-9.

22 Bradley TD, Brown IG, Zamel N, Phillipson EA, Hoffstein V. Differences in pharyngeal properties between snorers with predominantly central sleep apnea and those without sleep apnea. Am Rev Respir Dis 1987;135:387-91.
23 Brown IG, Bradley TD, Phillipson EA, Zamel N, Hoffstein V. Pharyngeal compliance in snoring subjects with and without obstructive sleep apnea. Am Rev Respir Dis 1985;132:211-5.

24 Lugaresi E, Cirignotta F, Coccagna G, Piana C. Some epidemiological data on snoring and cardiocirculatory disturbances. Sleep 1980;3:221-4.

25 Koskenvuo M, Partinen M, Sarna S, Kaprio J, Langinvainio H, Heikkilä K. Snoring as a risk factor for hypertension and angina pectoris. Lancet 1985 ;ii:893-6.

26 Riley R, Powell N, Guilleminault C. Cephalometric roentgenograms and computerized tomographic scans in obstructive sleep apnea. Sleep 1986;9:514-5.

27 Brown IG, Zamel N, Hoffstein V. Pharyngeal cross-sectional area in normal men and women. J Appl Physiol 1986; 61:890-5.

28 Mueller WH, Wohlleb JC. Anatomical distribution of subcutaneous fat and its description by multivariate methods: How valid are principal components? American Journal of Physical Anthropology 1981;54:25-35.

29 Horner RL, Mohiaddin RH, Lowell DG, et al. Sites and sizes of fat deposit around the pharynx in obese patients with obstructive sleep apnoea and weight match controls. Eur Respir J 1989;2:613-22.

30 Guilleminault C, Riley R, Powell N. Obstructive sleep apnea and cephalometric roentgenograms. Am Rev Respir Dis 1984;130:145-6.

31 Riley R, Powell N, Guilleminault C, Nino-Murcia G. Maxillary, mandibular, and hyoid advancement: an alternative to tracheostomy in obstructive sleep apnea syndrome. Otolaryngol Head Neck Surg 1986;94:584-8.

32 Önal E, Lopata M, O'Connor T. Pathogenesis of apneas in hypersomnia-sleep apnea syndrome. Am Rev Respir Dis 1982;125:167-74.

33 Sériès F, Cormier Y, Desmeules M, La Forge J. Effects of respiratory drive on upper airways in sleep apnea patients and normal subjects. $J$ Appl Physiol 1989;67:973-9.

34 Fitzpatrick MF, Yildirim Y, Jalleh R, Wightman AJA, Douglas NJ. Posture affects cephalometric measurements in patients with obstructive sleep apnoea [abstract]. $\mathrm{Am}$ Rev Respir Dis 1990;141:A858.

35 Sériès F, Cormier $\mathbf{Y}$, Desmeules $\mathrm{M}$. Influence of passive changes of lung volume on upper airways. J Appl Physiol 1990;68:2159-64. 